\title{
Impact of exercise on hippocampal neurogenesis in hyperglycemic diabetes
}

\author{
Chae-Bin Lee, Seung-Soo Baek* \\ Department of Sport \& Health Care, College of Art \& Culture, Sangmyung University, Seoul, Korea
}

Hyperglycemic diabetes is a chronic metabolic disorder characterized by high level of plasma glucose. Numerous studies have shown that hyperglycemic diabetes leads to brain dysfunction including cognitive impairment and emotional disorders. This study evaluated the impact of exercise on brain dysfunction, hippocampal neurogenesis, and cognitive impairment in hyperglycemic diabetes. The present study suggests that exercise improves hyperglycemic control and prevents decline of cognition through increasing hippocampal neurogenesis. Understanding the mechanism of exercise for hippocampal neurogenesis can lead to the development of therapeutic strategies for metabolic disorders.

Keywords: Diabetes, Hyperglycemia, Neurogenesis, Cognitive impairment, Exercise

\section{INTRODUCTION}

Hyperglycemic diabetes can be defined as a chronic metabolic disorder characterized by hyperglycemia. Impaired glucose metabolism can be resulted from inappropriate insulin secretion, insulin resistance, and acute stress. Diabetes leads to severe complications affecting different organs including the heart, kidney, eye, and brain. The effects of metabolic disorders such as diabetes and obesity have been shown on the central nervous system (Ji et al., 2013; Qizilbash et al., 2015). Diabetic brain complications are associated with cognitive decline and depression. Diabetes patients have increased vulnerability to cognitive impairment (Ho et al., 2013).

Exercise can promote energy metabolism, reduce insulin resistance, and control glucose homeostasis. Exercise is considered an effective strategy to reduce glucose level and diabetes symptom. Exercise-induced improvement in learning and memory can be considered as exercise-dependent neural plasticity and hippocampal neurogenesis (Baek, 2016). However, we have not fully understood the effects of exercise on neurogenesis and cognitive function in hyperglycemic diabetes.

\section{EXERCISE AND BRAIN DYSFUNCTION IN HYPERGLYCEMIC DIABETES}

Hyperglycemic diabetes affects the brain function. Blockade of brain glucose transport or astrocytic glucose metabolism inhibits learning and memory (McNay et al., 2000). Impaired brain glucose homeostasis interferes with learning process and memory consolidation (Duarte, 2015). Insulin receptors are generally expressed in the brain, especially in the hippocampus. Impaired insulin signaling is believed to be associated with increasing Tau phosphorylation by reducing phosphorylation of protein kinase B (Akt) and glycogen synthase kinase 3 (Schubert et al., 2004). Ddiabetes changes integrity of a brain region mediating learning and memory, inducing defect of long-term potential in the hippocampus (Trudeau, 2004). Impaired hippocampal-dependent spatial learning and memory observed in hyperglycemia-induced diabetic animals (Kim et al., 2014; Kim et al., 2016).

Normalization of brain energy metabolism is a crucial factor to counteract central insulin sensitivity and synaptic plasticity associated with type-2 diabetes (Agrawal et al., 2014). Treadmill exercise alleviates memory loss in the streptozotocin (STZ)-induced
${ }^{*}$ Corresponding author: Seung-Soo Baek (iD https://orcid.org/0000-0002-1340-2098 Department of Sport \& Health Care, College of Art \& Culture, Sangmyung University, 20 Hongjimun 2-gil, Jongno-gu, Seoul 03016, Korea E-mail: ssoop@smu.ac.kr

Received: February 12, 2020 / Accepted: March 25, 2020
This is an Open Access article distributed under the terms of the Creative Commons Attribution Non-Commercial License (https://creativecommons.org/licenses/by-nc/4.0/) which permits unrestricted non-commercial use, distribution, and reproduction in any medium, provided the original work is properly cited. 
diabetic rats (Kim et al., 2016). Exercise protects central nervous system injury and improves learning ability and memory function (Lee et al., 2018; Sim, 2014). Aerobic exercise promotes the expression of synaptic plasticity-associated proteins in the hippocampus of diabetic rats (Li et al., 2019).

\section{EXERCISE AND HIPPOCAMPAL NEUROGENESIS IN HYPERGLYCEMIC DIABETES}

Diabetes negatively affects the morphological integrity of the hippocampus and reduces hippocampal neurogenesis (Ho et al., 2013). Hyperglycemic diabetes reduces expression of dendritic spines and synaptic proteins and increases markers of apoptosis in the hippocampus of the brain (Ho et al., 2013). STZ-induced hyperglycemic diabetes suppresses hippocampal neurogenesis in rodents (Kim et al., 2016). Decreased hippocampal neurogenesis and neuroplasticity is associated with cognitive impairment and depressive behavior (Baek, 2016).

Regular exercise alleviated memory impairment through enhancing cell proliferation in the hippocampus in hyperglycemic diabetes (Kim et al., 2014). Treadmill exercise alleviates Alzheimer disease-associated memory loss by increasing neurogenesis through activating Wnt signaling pathway in the diabetic rats (Kim et al., 2016). Physical exercise increases the number of neuronal and non-neuronal cortical cells and hippocampal neuronal cells in adolescent rats (Victorino et al., 2017). Neurogenesis can be an important contributor to improving learning and memory through exercise (Baek, 2016; Li et al., 2019).

\section{EXERCISE AND COGNITIVE IMPAIRMENT IN HYPERGLYCEMIC DIABETES}

In a type 2 analogous model such as the Zucker diabetic rat, hyperglycemia was significantly increased and cognitive function was decreased compared to the nondiabetic Zucker rat (Yi et al., 2009). Diabetes mellitus is considered as a risk factor for Alzheimer disease (Baek et al., 2016). Short-term memory and spatial learning ability were deteriorated by induction of diabetes (Kim et al., 2016).

In addition to improved glycemic control, exercise could also contribute to increased hippocampal neuronal production by enhancing brain-derived neurotrophic factor, insulin-like growth factor-1 and vascular endothelial growth factor (van Praag, 2008). Exercise can improve cognitive function in dementia patients and

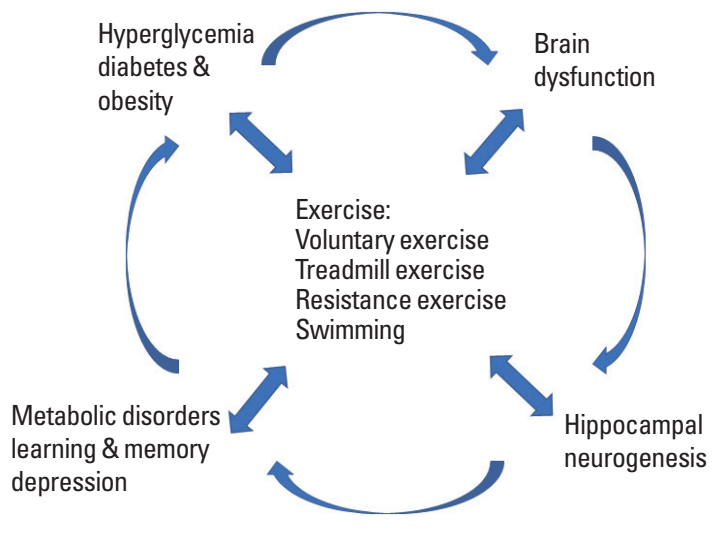

Fig. 1. Impact of exercise on brain function in diabetes.

reduce the risk of dementia (McDonnell et al., 2011). People with hyperglycemic diabetes who participate in exercise programs may improve glucose metabolism and have a positive effect on mood (de Groot et al., 2012). Treadmill running improved spatial memory in Morris water maze and in 8-arms maze test through activation brain-derived neurotrophic factor activation (Heo et al., 2014; Seo et al., 2013).

\section{CONCLUSIONS}

This study showed evidence of the effect of exercise to improve cognition by increasing neurogenesis (Fig. 1). The beneficial role of exercise may be a valuable treatment to improve brain cell dysfunction in hyperglycemic diabetes by increasing neuronal cell proliferation. Understanding the mechanism of exercise for hippocampal neurogenesis can lead to the development of therapeutic strategies for metabolic disorders.

\section{CONFLICT OF INTEREST}

No potential conflict of interest relevant to this article was reported.

\section{ACKNOWLEDGMENTS}

This work was supported by 2018 Sangmyung University Research Foundation of Korea.

\section{REFERENCES}

Agrawal R, Zhuang Y, Cummings BP, Stanhope KL, Graham JL, Havel PJ, Gomez-Pinilla F. Deterioration of plasticity and metabolic homeo- 
stasis in the brain of the UCD-T2DM rat model of naturally occurring type-2 diabetes. Biochim Biophys Acta 2014;1842:1313-1323.

Baek SS. Role of exercise on the brain. J Exerc Rehabil 2016;12:380-385.

Baek SS, Kim SH. Treadmill exercise ameliorates symptoms of Alzheimer disease through suppressing microglial activation-induced apoptosis in rats. J Exerc Rehabil 2016;12:526-534.

de Groot M, Doyle T, Kushnick M, Shubrook J, Merrill J, Rabideau E, Schwartz F. Can lifestyle interventions do more than reduce diabetes risk? Treating depression in adults with type 2 diabetes with exercise and cognitive behavioral therapy. Curr Diab Rep 2012;12:157-166.

Duarte JM. Metabolic alterations associated to brain dysfunction in diabetes. Aging Dis 2015;6:304-321.

Heo YM, Shin MS, Kim SH, Kim TW, Baek SB, Baek SS. Treadmill exercise ameliorates disturbance of spatial learning ability in scopolamine-induced amnesia rats. J Exerc Rehabil 2014;10:155-161.

Ho N, Sommers MS, Lucki I. Effects of diabetes on hippocampal neurogenesis: links to cognition and depression. Neurosci Biobehav Rev 2013;37:1346-1362.

Ji ES, Ko IG, Cho JW, Davis RW, Hwang GY, Jee YS, Lim BV. Treadmill exercise inhibits apoptotic neuronal cell death with suppressed vascular endothelial growth factor expression in the retinas of the diabetic rats. J Exerc Rehabil 2013;9:348-353.

Kim DY, Jung SY, Kim K, Kim CJ. Treadmill exercise ameliorates Alzheimer disease-associated memory loss through the Wnt signaling pathway in the streptozotocin-induced diabetic rats. J Exerc Rehabil 2016; 12:276-283.

Kim YH, Sung YH, Lee HH, Ko IG, Kim SE, Shin MS, Kim BK. Postnatal treadmill exercise alleviates short-term memory impairment by enhancing cell proliferation and suppressing apoptosis in the hippocampus of rat pups born to diabetic rats. J Exerc Rehabil 2014;10:209-217.

Lee JM, Kim TW, Park HS, Park SS, Shin MS, Sung YH, Seo TB, Kim YP. Effects of exercise on sexual function and central mechanism in the streptozotocin-induced diabetic rats. J Exerc Rehabil 2018;14:10-15.

Li J, Liu Y, Liu B, Li F, Hu J, Wang Q, Li M, Lou S. Mechanisms of aerobic exercise upregulating the expression of hippocampal synaptic plasticity-associated proteins in diabetic rats. Neural Plast 2019;2019:7920540.
McDonnell MN, Smith AE, Mackintosh SF. Aerobic exercise to improve cognitive function in adults with neurological disorders: a systematic review. Arch Phys Med Rehabil 2011;92:1044-1052.

McNay EC, Fries TM, Gold PE. Decreases in rat extracellular hippocampal glucose concentration associated with cognitive demand during a spatial task. Proc Natl Acad Sci U S A 2000;97:2881-2885.

Qizilbash N, Gregson J, Johnson ME, Pearce N, Douglas I, Wing K, Evans SJW, Pocock SJ. BMI and risk of dementia in two million people over two decades: a retrospective cohort study. Lancet Diabetes Endocrinol 2015;3:431-436.

Schubert M, Gautam D, Surjo D, Ueki K, Baudler S, Schubert D, Kondo T, Alber J, Galldiks N, Küstermann E, Arndt S, Jacobs AH, Krone W, Kahn $\mathrm{CR}$, Brüning JC. Role for neuronal insulin resistance in neurodegenerative diseases. Proc Natl Acad Sci U S A 2004;101:3100-3105.

Seo TB, Cho HS, Shin MS, Kim CJ, Ji ES, Baek SS. Treadmill exercise improves behavioral outcomes and spatial learning memory through up-regulation of reelin signaling pathway in autistic rats. J Exerc Rehabil 2013;9:220-229.

Sim YJ. Treadmill exercise alleviates impairment of spatial learning ability through enhancing cell proliferation in the streptozotocin-induced Alzheimer's disease rats. J Exerc Rehabil 2014;10:81-88.

Trudeau F, Gagnon S, Massicotte G. Hippocampal synaptic plasticity and glutamate receptor regulation: influences of diabetes mellitus. Eur J Pharmacol 2004;490:177-186.

van Praag H. Neurogenesis and exercise: past and future directions. Neuromolecular Med 2008;10:128-140.

Victorino AB, Serra FT, Piñero PP, de Almeida AA, Lopim GM, Matias Junior I, Machado HR, Lent R, Cabral FR, Gomez-Pinilla F, Arida RM, Gomes da Silva S. Aerobic exercise in adolescence results in an increase of neuronal and non-neuronal cells and in mTOR overexpression in the cerebral cortex of rats. Neuroscience 2017;361:108-115.

Yi SS, Hwang IK, Yoo KY, Park OK, Yu J, Yan B, Kim IY, Kim YN, Pai T, Song W, Lee IS, Won MH, Seong JK, Yoon YS. Effects of treadmill exercise on cell proliferation and differentiation in the subgranular zone of the dentate gyrus in a rat model of type II diabetes. Neurochem Res 2009;34:1039-1046. 